\title{
Dietary and modifiable factors contributing to hyper-LDL-cholesterolemia prevalence in nationwide time series data and the implications for primary prevention strategies
}

\author{
Inkyung Baik ${ }^{\S}$ \\ Department of Foods and Nutrition, College of Science and Technology, Kookmin University, 77, Jeongnung-ro, Seongbuk-gu, Seoul 02707, Korea
}

BACKGROUND/OBJECTIVES: A number of studies examined secular trends in blood lipid profiles using time series data of national surveys whereas few studies investigated individual-level factors contributing to such trends. The present study aimed to examine secular trends in dietary and modifiable factors and hyper-LDL-cholesterolemia (HC) prevalence and evaluate their associations using time series data of nationwide surveys.

SUBJECTS/METHODS: The study included 41,073 Korean adults aged $\geq 30$ years from the 2005, 2007-2009, 2010-2012, 2013-2015, and 2016 Korea National Health and Nutrition Examination Surveys. Stepwise logistic regression analysis was performed to select significant factors associated with $\mathrm{HC}$, which was defined as serum LDL cholesterol levels $\geq 130 \mathrm{mg} / \mathrm{dL}$.

RESULTS: The following factors showed a positive association with $\mathrm{HC}(P<0.05)$ : for men having higher body mass index (BMI), being married, having an office job, and consuming higher dairy and vegetable oil products; for women having higher age or BMl, having no job or a non-office job, not in a low-income household, and consuming higher dairy products. In the given model, the 2016 survey data showed that a $2 \mathrm{~kg} / \mathrm{m}^{2}$ reduction in BMl of obese persons resulted in a decreased HC prevalence from $30.8 \%$ to $29.3 \%$ among men and from $33.6 \%$ to $32.5 \%$ among women.

CONCLUSIONS: Based on these findings, it is suggested that primary prevention programs should advocate having proper BMI for Korean adults with a high-risk of HC. However, whether discouraging consumption of dairy and vegetable oil products can reduce HC prevalence warrants further studies with a prospective longitudinal design.

Nutrition Research and Practice 2020;14(1):62-69; https://doi.org/10.4162/nrp.2020.14.1.62; pISSN 1976-1457 elSSN 2005-6168

Keywords: Surveys, cholesterol, prevalence, body mass index

\section{INTRODUCTION}

Hypercholesterolemia is a condition characterized by abnormally high levels of total cholesterol in the blood and particularly LDL cholesterol is a major component to increase the risk of coronary heart disease (CHD) [1]. Earlier studies have suggested that an $1 \%$ increase in the total cholesterol (TC) level may result in a $2 \%$ increased risk of CHD [2], whereas every $1 \mathrm{mg} / \mathrm{dL}$ decrease in $\mathrm{HDL}$ cholesterol may lead to a $2-3 \%$ increase in $\mathrm{CHD}$ risk [3].

Based on the Cause of Death Statistics data, the CHD mortality rate in Korea is known to have markedly increased over 30 years [4]. The 2016 Korea National Health and Nutrition Examination Survey (KNHANES) has shown that $20.6 \%$ of male and $23.6 \%$ of female adults aged 30 years or older have hypercholesterolemia defined as TC levels $\geq 240 \mathrm{mg} / \mathrm{dL}$ [5], which is a three-fold increase from 2005 (7.3\% in men and $8.4 \%$ in women). In contrast, the blood levels of HDL cholesterol and triglycerides did not change significantly during the similar period [5,6]. Given these reports, a rising trend in LDL cholesterol levels is likely and may be responsible for the increased CHD morbidity and mortality in Korea.

Health-related associations, organizations, and societies in Korea have made concerted efforts to control CHD risk factors. They have provided the guideline for the management of dyslipidemia emphasizing the use of lipid-lowering medications and lifestyle modifications including smoking cessation and dietary changes, which can improve LDL cholesterol levels [7]. In terms of dietary recommendations, they have advocated dietary fat intake less than $30 \%$ (saturated fat intake less than $7 \%$ ) of total caloric intake and replacement of saturated fat with polyunsaturated fat in the diet [7]. A recent report, in which the KNHANES data from 1998 to 2015 were analyzed, has shown an increasing secular trend in the mean percent of calories from dietary fat (fat \%) from $18 \%$ to $21 \%$ in male adults and from $16 \%$ to $19 \%$ in female adults [8]. However, it is questionable

\footnotetext{
This study was supported by National Research Foundation of Korea Grant funded by the Korean Government (NRF-2017R1A2A2A05001380). The funders have no role in the study.

${ }^{\S}$ Corresponding Author: Inkyung Baik, Tel. 82-2-910-4774, Fax. 82-2-910-5249, Email. ibaik@kookmin.ac.kr

Received: April 17, 2019, Revised: June 13, 2019, Accepted: November 14, 2019

This is an Open Access article distributed under the terms of the Creative Commons Attribution Non-Commercial License (http://creativecommons.org/licenses/by-nc/3.0/ which permits unrestricted non-commercial use, distribution, and reproduction in any medium, provided the original work is properly cited.
} 
whether these increasing trends coincide with a secular trend in LDL cholesterol levels and whether such consumption, which is commonly observed in Asian populations [9], is associated with the individual-level prevalence of hyper-LDL-cholesterolemia (HC). Because the KNHANES data do not include information on the types of dietary fat, a secular trend in saturated fat intake is obscure.

A number of studies from different countries examined secular trends in lipid profiles [10-16]. One of them reported lifestyle factors contributing to such trends, including obesity, smoking, and alcohol drinking, but did not examine dietary factors [16]. Another study observed similar secular trends in serum cholesterol levels and dietary fat intake, but did not analyze their association [13].

Time series analysis of national health survey data is useful for monitoring secular trends in disease prevalence and related factors, establishing contemporary strategies and plans to improve health, and projecting a future estimate of disease burden. Based on results from the analysis, effective programs where lifestyle changes are essential for the prevention and management of chronic disease can be established [17].

The objectives of the present study, which used pooled cross-sectional data of nationwide surveys over 10 years, are as follows: 1) to examine secular trends in dietary and lifestyle factors (such as smoking, alcohol consumption, or sleep duration), other factors (such as demographic, socioeconomic, or psychological factors), and HC prevalence; 2) to evaluate the association between these factors and $\mathrm{HC}$ prevalence at the individual-level; 3) to construct a prediction model which includes significant factors contributing to $\mathrm{HC}$ prevalence; 4) to suggest implications for primary prevention strategies against $\mathrm{HC}$ based on the prediction model.

\section{SUBJECTS AND METHODS}

\section{Study population}

The present study obtained times series data from the website of the KNHANES (https:// knhanes.cdc.go.kr/knhanes) and the Korean Statistical Information Service (KOSIS) (http://kosis.kr). Individual level data from the KNHANES and regional level data from the KOSIS for the period between 1998 and 2016 were obtained when accessed in May of 2018. A previous report described the KNHANES, which is a cross-sectional study [18]. Briefly, this nationwide health survey collects information on socioeconomic status, quality of life, health behaviors, dietary intake and behaviors, anthropometric and clinical measures, and biochemical profiles. The survey regarding health behaviors including smoking and alcohol drinking is self-administered while other survey processes are administered by trained researchers. A single 24-hour dietary recall and a qualitative food frequency table consisting of 63 food items are used in an interview to collect dietary information [18] and average daily nutrient intakes are calculated mainly based on the food composition database published by Rural Development Administration of Korea [19].

The present study used data of the KNHANES cycles III-VI (2005, 2007-2009, 2010-2012, and 2013-2015, respectively) and VII (only the year 2016) with a particular focus on the health and nutrition interview records. Because information on the use of cholesterol-lowering medications was available from the cycle III, earlier data were not used. After the cycle III-VI data for 41,864 participants aged 30 years or older were merged, data for 41,073 participants who had lipid profiles were used to analyze secular trends in variables. After excluding 2,679 $\mathrm{HC}$ patients, who reported the use of cholesterol-lowering medications or treatments, to minimize potential influence of $\mathrm{HC}$ diagnosis on lifestyle factors, data for 38,394 participants $(15,634$ men and 22,760 women) were used in analysis identifying significant factors associated with $\mathrm{HC}$ prevalence and constructing prediction models. The data of the year 2016 comprising 4,001 participants (1,623 men and 2,378 women) was used to validate the prediction models.

All procedures were approved by the Human Subjects Review Committee of Kookmin University (KMU-201512-HR-094).

\section{Variables from the KNHANES data and the KOSIS data}

The outcome variable of the study was the prevalence of $\mathrm{HC}$ that was defined as having serum LDL cholesterol levels $\geq 130$ $\mathrm{mg} / \mathrm{dL}$ or diagnosed $\mathrm{HC}$, because LDL cholesterol is the primary target of dylipidemia management and reducing CHD risk [7]. LDL cholesterol levels were calculated using the Friedewald equation [20]. The initial list of potential factors contributing to $\mathrm{HC}$ was prepared based on the similar procedure that a previous study used [22] and reviewed by an expert council consisting of nutritionists, public health specialists, epidemiologists, and physicians. Based on the list revised by the expert council, variables available in the KNHANES, including age, gender, marital status, job status, income status, body mass index (BMI), smoking status, alcohol consumption status, sleep duration, psychological status, use of oral contraceptives (OC) in women, and dietary variables from 24-hour dietary recalls, were selected. For dietary variables, calculated total calorie (kcal/day), fat (g/day) intake, and consumption of high-fat food items (g/day), such as meats, eggs (due to high cholesterol content), dairy products, nuts, plant oils, and animal fats and oils, which had been classified in the KNHANES data, were selected. Variables regarding physical activity were not collected because survey questions on this topic were inconsistent across survey cycles. The KOSIS data regarding gasoline consumer price index, which may indirectly reflect physical activity [21], were extracted, merged with the KNHANES data according to 16 residence regions, and treated as a regional level variable.

\section{Statistical analysis}

Descriptive statistics were performed and $p$ for trend across the KNHANES data cycles was obtained using the Chi-square test for trend (Cochran-Armitage test) and linear trend analysis in ANOVA. To analyze the associations between contributing factors and $\mathrm{HC}$ prevalence, logistic regression analysis was used. The model was constructed using the equation, $\mathrm{P}(\mathrm{Oijt}=1)=\int$ $\left(a+\beta 1^{*} X i t+\beta 2^{*} Z j t+\beta 3^{*} T\right)$, in which ' $O^{\prime}$ indicates an outcome variable; ' $i$ ', an individual; ' $j$ ', residence region; ' $t$ ', year; ' $X$ ', contributing factors for an individual subject; ' $Z$ ', a variable from the KOSIS data; ' $T$ ', yearly ranking; and ' $\int()^{\prime}$ ', a logit probability function. In this analysis, survey sample weights were given to the KNHANES. Based on such a model which was used in 
previous studies [22,23], whether time, individual level variables, and region level variables are associated with $\mathrm{HC}$ prevalence was evaluated.

Among contributing factors, age, BMl, and consumption of high-fat foods were treated as continuous variables while marital status (single or married), job status (office job, non-office job, or no job), income status (low-income or higher-income household), smoking status (non-smoker or ever-smoker), alcohol consumption status (alcohol non-drinker or drinker), sleep duration ( $\leq 6$ hours/day or $>6$ hours/day), experiencing stress (no or yes), having depressed mood (no or yes), and OC use in women (no or yes) were treated as categorical variables in gender-specific models. Because there were trivial missing data in some dummy variables, individuals with a missing value were classified into a group with a higher frequency. To further analyze the association between fat \% and $\mathrm{HC}$ prevalence, all of these variables, except for consumption of high-fat foods, were included in the multi-variable models. Total calorie intake, fat $\%$, and consumption of high-fat foods were not controlled for simultaneously to avoid collinearity.
To identify the factors contributing to HC prevalence, significant independent variables were found at the level of 0.05 after variables were selected using a stepwise selection method (slentry $=0.15$ and slstay $=0.15$ ). Multivariable odds ratios (ORs) and its $95 \%$ confidence interval $(\mathrm{Cl})$ were obtained from the final gender-specific models. Coefficient estimates for significant variables were used to construct prediction models. To estimate HC prevalence for the year 2016, independent variables were selected from the 2016 KNHANES data.

\section{RESULTS}

Secular trends in hyper-LDL-cholesterolemia prevalence and dietary and modifiable factors

Table 1 shows the age-adjusted values of variables from the KNHANES data and the KOSIS data across the survey cycles. Age-adjusted HC prevalence increased over the 10-year cycles $(P<0.001)$. Proportions of people who were married, those with low income, smokers, alcohol drinkers, persons who admitted to experiencing stress or depression, and users of $O C$ decreased

Table 1. Comparison of age and age-adjusted values of variables in 41,073 adults aged 30 years or older across survey cycles of the KNHANES data and the KOSIS data

\begin{tabular}{|c|c|c|c|c|c|}
\hline \multirow{2}{*}{ Variables } & \multicolumn{4}{|c|}{ Survey cycles (year) } & \multirow{2}{*}{$P$ for trend } \\
\hline & $3^{\text {rd }}(2005)$ & $4^{\text {th }}(2007-2009)$ & $5^{\text {th }}(2010-2012)$ & $6^{\text {th }}(2013-2015)$ & \\
\hline \multicolumn{6}{|l|}{ KNHANES data } \\
\hline Participants (n) & 3,940 & 12,288 & 13,208 & 11,637 & \\
\hline Hyper-LDL-cholesterolemia (\%) & 32.7 & 34.5 & 37.3 & 36.9 & $<0.001$ \\
\hline Age (yrs) & 50.4 & 53.1 & 54.2 & 54.4 & $<0.001$ \\
\hline Male (\%) & 41.3 & 39.6 & 40.1 & 40.5 & 0.68 \\
\hline Married (\%) & 96.8 & 96.9 & 95.7 & 94.5 & $<0.001$ \\
\hline Office job worker (\%) & 12.7 & 14.4 & 18.4 & 20.0 & $<0.001$ \\
\hline Low-income household $^{1)}(\%)$ & 22.5 & 24.7 & 17.4 & 15.9 & $<0.001$ \\
\hline Body mass index $\left(\mathrm{kg} / \mathrm{m}^{2}\right)$ & 23.9 & 23.8 & 23.8 & 23.9 & 0.69 \\
\hline Body mass index $\geq 25 \mathrm{~kg} / \mathrm{m}^{2}(\%)$ & 33.5 & 32.6 & 32.5 & 33.7 & 0.05 \\
\hline Current smoker (\%) & 21.0 & 18.6 & 15.7 & 14.2 & $<0.001$ \\
\hline Alcohol drinker ${ }^{2)}(\%)$ & 69.1 & 66.3 & 67.5 & 66.4 & $<0.001$ \\
\hline Sleep duration $\leq 6$ hours/d (\%) & 41.4 & 42.5 & 43.4 & 47.7 & $<0.001$ \\
\hline Experiencing stress (\%) & 33.6 & 26.7 & 23.9 & 22.3 & $<0.001$ \\
\hline Having depressed mood (\%) & 16.5 & 16.2 & 12.7 & 7.8 & $<0.001$ \\
\hline Use of oral contraceptives ${ }^{3)}(\%)$ & 19.3 & 18.5 & 16.3 & 15.9 & $<0.001$ \\
\hline Calorie intake $(\mathrm{kcal} / \mathrm{d})$ & $1,919.8$ & $1,793.3$ & $1,940.1$ & $1,961.6$ & $<0.001$ \\
\hline Total fat intake $(\mathrm{g} / \mathrm{d})$ & 36.3 & 30.8 & 36.9 & 39.6 & $<0.001$ \\
\hline \multicolumn{6}{|l|}{ Consumption of high-fat foods } \\
\hline Meat $(g / d)$ & 72.8 & 67.8 & 82.8 & 84.5 & $<0.001$ \\
\hline Eggs $(g / d)$ & 18.5 & 17.1 & 20.5 & 23.9 & $<0.001$ \\
\hline Dairy products $(\mathrm{g} / \mathrm{d})$ & 50.5 & 54.7 & 74.4 & 74.7 & $<0.001$ \\
\hline Nuts $(g / d)$ & 4.63 & 3.01 & 5.79 & 9.28 & $<0.001$ \\
\hline Vegetable oil products (g/d) & 6.65 & 6.27 & 7.21 & 7.42 & $<0.001$ \\
\hline Animal fat products $(\mathrm{g} / \mathrm{d})$ & 1.75 & 0.07 & 0.12 & 0.17 & $<0.001$ \\
\hline \multicolumn{6}{|l|}{ KOSIS data } \\
\hline Consumer price index for gasoline & 82.7 & 94.1 & 109.3 & 102.7 & $<0.001$ \\
\hline
\end{tabular}

KNHANES, Korea National Health and Nutrition Examination Survey; KOSIS, Korean Statistical Information Service.

Hyper-LDL-cholesterolemia is defined as having serum LDL cholesterol levels $\geq 130 \mathrm{mg} / \mathrm{dL}$.

1) Based on monthly household income and the number of family members

${ }^{2)}$ Consumption of an alcoholic beverage at least once a month over the previous year

3) Among women

Number of participants (year): 3,940 (2005), 2,204 (2007), 4,803 (2008), 5,281 (2009), 4,423 (2010), 4,527 (2011), 4,258 (2012), 3,881 (2013), 3,832 (2014), 3,924 (2015)

$P$ for trend was obtained using the Chi-square test for trend (Cochran-Armitage test) and linear trend analysis in ANOVA. 
Table 2. Age-adjusted odds ratios for variables in the association with hyperLDL-cholesterolemia prevalence over a 10-year period in 15,634 male and 22,760 female adults

\begin{tabular}{|c|c|c|}
\hline Variables and unit (reference) & $\begin{array}{l}\text { OR }(95 \% \mathrm{Cl}) \\
\text { in men }\end{array}$ & $\begin{array}{c}\text { OR }(95 \% \mathrm{Cl}) \\
\text { in women }\end{array}$ \\
\hline Age, 5-year & $0.98(0.96,0.99)$ & $1.21(1.20,1.23)$ \\
\hline Survey cycle & $1.01(0.96,1.05)$ & $0.99(0.95,1.03)$ \\
\hline Body mass index $\left(\mathrm{kg} / \mathrm{m}^{2}\right)$ & $1.09(1.08,1.11)$ & $1.08(1.07,1.10)$ \\
\hline Married (no) $)^{1)}$ & $1.27(1.07,1.51)$ & $1.02(0.82,1.26)$ \\
\hline Office job (no job or non-office job) ${ }^{1)}$ & $1.15(1.04,1.28)$ & $0.80(0.72,0.89)$ \\
\hline Low-income household (no) ${ }^{1)}$ & $0.92(0.81,1.04)$ & $0.86(0.78,0.94)$ \\
\hline Ever-smoker (non-smoker) ${ }^{1)}$ & $0.97(0.88,1.07)$ & $1.00(0.89,1.14)$ \\
\hline Alcohol drinker (non-drinker) ${ }^{1)}$ & $0.90(0.81,1.01)$ & $1.02(0.95,1.11)$ \\
\hline Sleep duration $\leq 6 \mathrm{hr} / \mathrm{d}(>6 \mathrm{hr} / \mathrm{d})^{1)}$ & $1.03(0.94,1.11)$ & $1.01(0.94,1.09)$ \\
\hline Experiencing stress (no $)^{1)}$ & $1.01(0.92,1.11)$ & $1.01(0.93,1.09)$ \\
\hline Having a depressed mood (no) ${ }^{1)}$ & $0.98(0.83,1.14)$ & $1.09(0.99,1.20)$ \\
\hline Total fat intake $(\mathrm{g} / \mathrm{d})$ & $1.01(0.99,1.02)$ & $1.01(0.99,1.02)$ \\
\hline \multicolumn{3}{|l|}{ Consumption of high-fat foods ( $g / d$ ) } \\
\hline Meat & $1.00(0.97,1.03)$ & $0.98(0.95,1.01)$ \\
\hline Egg & $1.03(0.94,1.12)$ & $1.08(0.97,1.20)$ \\
\hline Dairy products & $1.05(1.02,1.08)$ & $1.05(1.02,1.08)$ \\
\hline Nuts & $0.86(0.72,1.02)$ & $0.96(0.83,1.11)$ \\
\hline Vegetable oil products & $1.06(1.02,1.11)$ & $1.03(0.98,1.07)$ \\
\hline Animal fat products & $1.12(0.92,1.35)$ & $0.89(0.71,1.10)$ \\
\hline Consumer price index for gasoline & $1.00(0.99,1.00)$ & $1.00(0.99,1.00)$ \\
\hline \multicolumn{3}{|c|}{$\begin{array}{l}\text { OR, Odds ratio; } \mathrm{Cl} \text {, confidence interval. } \\
\text { 1) The reference of a binary variable is expressed as opposed to the variable itself. } \\
\text { Number of participants (year): 3,882 (2005), 2,144 (2007), 4,616 (2008), 5,041 } \\
\text { (2009), 4,149 (2010), 4,182 (2011), 3,917 (2012), 3,550 (2013), 3,467 (2014), 3,446 } \\
\text { (2015) } \\
\text { Logistic regression analysis was used. }\end{array}$} \\
\hline
\end{tabular}

$(P<0.001)$, whereas proportions of office workers and those with short sleep duration increased $(P<0.001)$ over the cycles. The average daily consumption of meats, eggs, dairy products, nuts, and vegetable oil products increased with total calorie and fat intake $(P<0.001)$ whereas consumption of animal fat products decreased over the cycles $(P<0.001)$. Based on the KOSIS data, the gasoline consumer price index had increased $(P<0.001)$

Associations between dietary and modifiable factors and hyper-LDL-cholesterolemia prevalence

The results of stepwise regression analysis for the 10-year prevalence of $\mathrm{HC}$ are presented in Tables 2 and 3. Table 2 shows age-adjusted ORs and $95 \% \mathrm{Cl}$ for all variables by gender. Age, $\mathrm{BMl}$, marital status, types of job, and consumption of dairy products and vegetable oil products were significant in men and age, BMI, types of job, income status, and dairy product intake were significant in women for the association with $\mathrm{HC}$ $(P<0.05)$.

Table 3 shows the gender-specific final models after conducting stepwise logistic regression analysis, which included all variables presented in Table 2, except for fat intake. Finally, BMl, marital status, types of job, and consumption of dairy products and vegetable oil products in men and age, BMI, types of job, income status, and dairy product intake in women were selected as significant variables $(P$-value $<0.001$ in the Wald
Table 3. Results of stepwise logistic regression analysis for the association between significant factors and hyper-LDL-cholesterolemia prevalence over 10 -year period in 15,634 male and 22,760 female adults

\begin{tabular}{lcc}
\hline \multicolumn{1}{c}{ Variables and unit (reference) } & $\begin{array}{c}\text { Coefficient } \\
\text { estimates }\end{array}$ & OR $^{1)}(95 \% \mathrm{Cl})$ \\
\hline In 15,634 men & 0.085 & $1.09(1.07,1.10)$ \\
Body mass index $\left(\mathrm{kg} / \mathrm{m}^{2}\right)$ & 0.176 & $1.19(1.01,1.41)$ \\
Married (not married) ${ }^{2)}$ & 0.112 & $1.12(1.01,1.24)$ \\
Office job (no job or non-office job) $)^{2)}$ & 0.046 & $1.05(1.02,1.08)$ \\
Dairy product consumption, $100 \mathrm{~g} / \mathrm{d}$ & 0.052 & $1.05(1.01,1.10)$ \\
Vegetable oil product consumption, $10 \mathrm{~g} / \mathrm{d}$ & & \\
In 22,760 women & 0.037 & $1.04(1.03,1.04)$ \\
Age (yrs) & 0.081 & $1.09(1.07,1.10)$ \\
Body mass index (kg/m $\left.{ }^{2}\right)$ & -0.184 & $0.83(0.75,0.93)$ \\
Office job (no job or non-office job) $)^{2)}$ & -0.159 & $0.85(0.78,0.94)$ \\
Low-income household (no) ${ }^{2)}$ & 0.057 & $1.06(1.03,1.09)$ \\
Dairy product consumption, 100g/d & & \\
\hline OR, Odds ratio; Cl, confidence interval. &
\end{tabular}

test). On the basis of the multivariate results, men who were married, had higher BMI, an office job, and consumed more dairy and vegetable oil products, and women who were older, had higher BMI, no job or non-office job, higher income, and consumed more dairy products showed higher probabilities of having $\mathrm{HC}$.

\section{Prediction of hyper-LDL-cholesterolemia prevalence}

Using the gender-specific models demonstrated in Table 3, the observed and predicted estimates of $\mathrm{HC}$ prevalence for the year 2016 in male and female adults aged 30 years or older are shown in Fig. 1. The predicted estimates indicated as 'predicted prevalence $\mathrm{A}^{\prime}$ were $30.8 \%(95 \% \mathrm{Cl}$ : 30.4, 31.2) for men and $33.6 \%$ (95\% Cl: $32.8,34.3)$ for women. These predictions were comparable to the observed estimates of $32.8 \%(95 \% \mathrm{Cl}$ : $30.3,35.4)$ for men and $33.8 \%$ (95\% Cl: $31.5,36.2)$ for women.

Because the gender-specific final models included BMI, which is a well-known modifiable risk factor, as shown in Table 3, HC prevalence estimates were calculated under the assumption that $\mathrm{BMI}$ is reduced. After applying a reduction in body weight (a $2 \mathrm{~kg} / \mathrm{m}^{2}$ decrease in $\mathrm{BMI}$ ) to the prediction models, the modified estimates, indicated as 'predicted prevalence $\mathrm{B}^{\text {', were }}$ 29.3\% (95\% Cl: 28.9, 29.7) for men and 32.5\% (95\% Cl: 31.8, 33.3) for women. Because the obesity prevalence of $43 \%$ in men and $32 \%$ in women was considered in this calculation, a reduction in $\mathrm{HC}$ prevalence was found to be greater in men than in women.

\section{Association between fat intake and hyper-LDL-cholesterolemia prevalence}

Fig. 2 demonstrates the association between fat \% and HC prevalence after the adjustment of variables presented in Table 


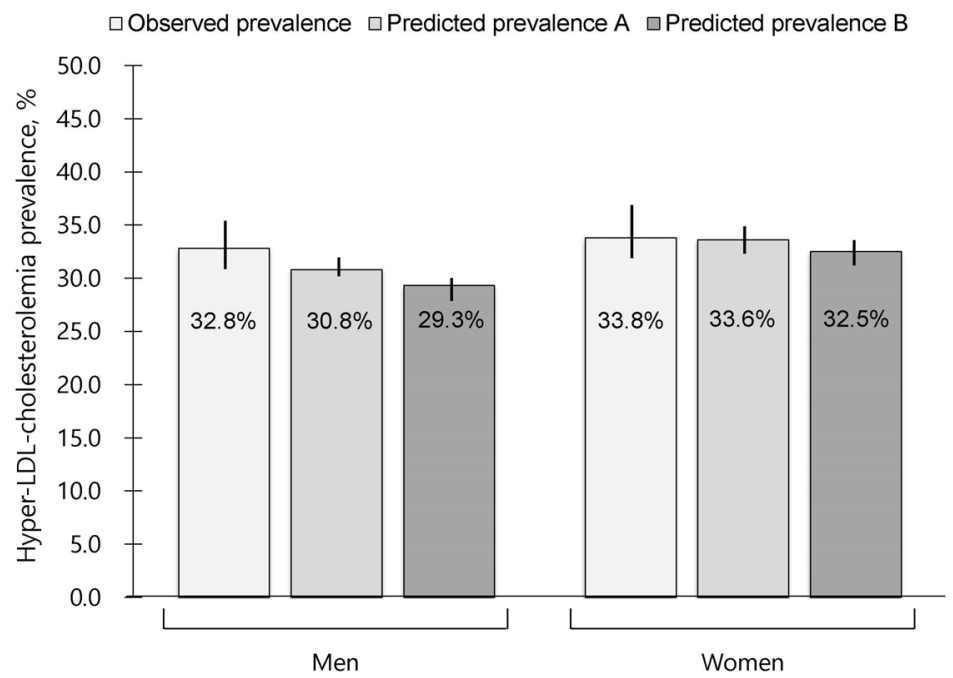

Fig. 1. Observed and predicted estimates of hyper-LDL-cholesterolemia prevalence calculated using the 2016 Korea National Health and Nutrition Examination Survey data. The 'predicted prevalence A' indicates an estimate calculated using the final models presented in Table 3. The 'predicted prevalence B' indicates an estimate obtained when considering a $2 \mathrm{~kg} / \mathrm{m}^{2}$ reduction in the body mass index of obese persons in the given models. The vertical line on the bar indicates the $95 \%$ confidence interval. Logistic regression analysis was used.

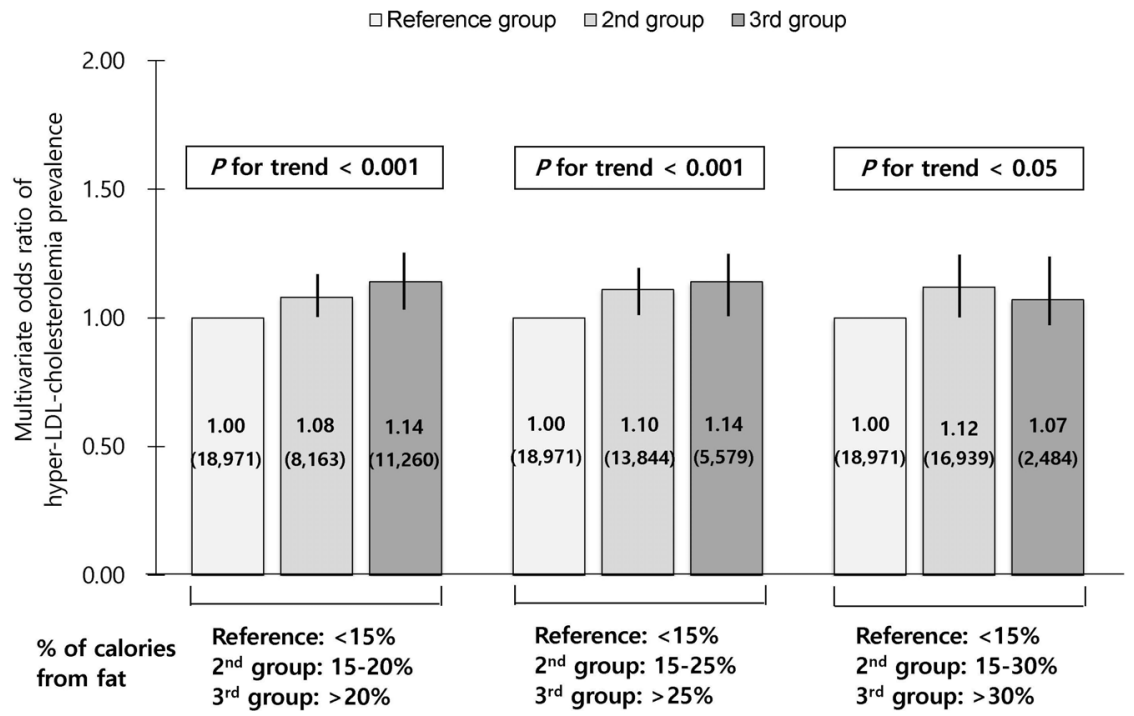

Fig. 2. Association between $\%$ of calories from fat and hyper-LDL-cholesterolemia prevalence in 38394 adults aged 30 years or older. The multivariate odds ratios of hyper-LDL-cholesterolemia prevalence were estimated after adjustment of variables presented in Table 2, except for consumption of high-fat foods. The multivariate odds ratios (number of subjects) are shown inside the bars with the $95 \%$ confidence interval depicted as a vertical line on the bar. Logistic regression analysis was used and p-value for trend was obtained when median values of $\%$ of calories from fat for each category were fitted.

2, except for consumption of high-fat foods. Three options for the fat \% categories were used in the models; 1$)<15 \%, 15-20 \%$, and $>20 \%$; 2) $<15 \%, 15-25 \%$, and $>25 \%$; 3) $<15 \%, 15-30 \%$, and $>30 \%$. Compared with the reference with $<15 \%$ of fat calories, the multivariable ORs $(95 \% \mathrm{Cl})$ were $1.08(1.01,1.16)$ for $15-20 \%$ and $1.14(1.07,1.22)$ for $>20 \%$ ( $P$-value for trend $<0.001), 1.10(1.04,1.18)$ for $15-25 \%$ and $1.14(1.04,1.24)$ for $>25 \%$ ( $P$-value for trend $<0.001)$, and $1.12(1.05,1.19)$ for $15-30 \%$ and $1.07(0.95,1.20)$ for $>30 \%$ of fat calories ( $P$-value for trend $<0.05$ ). Persons who consumed $>20 \%$ or $>25 \%$ of fat calories had a $14 \%$ significant increase in the OR of HC prevalence compared with those consuming $<15 \%$. Compared with the same reference, however, those consumed $>30 \%$ of fat calories showed a $7 \%$ increase in the OR, which was not significant partly due to a small sample size.

\section{DISCUSSION}

In the present study, after analyzing national survey data from 2005 to 2015, BMl and dairy product consumption were found to be significant modifiable factors positively associated with $\mathrm{HC}$ prevalence in both male and female adults. The prediction models including these factors, which were constructed and validated in the study, indicated that moderate weight loss in 
obese individuals could result in an 1 to 1.5 -fold reduction in $\mathrm{HC}$ prevalence.

The age-standardized prevalence of hypercholesterolemia defined as TC levels $\geq 240 \mathrm{mg} / \mathrm{dL}$ has been slowly increasing from 2005 to 2016; the KNHANES data revealed 8.0\% in 2005 and $19.9 \%$ in 2016 among all adults aged 30 years or older [5]. The prevalence of hypercholesterolemia in U.S. adults aged 20 years or older was reported to be $12.4 \%$ in $2015-2016$ [24] whereas comparable data for same-aged Korean adults reported $17.2 \%$. Furthermore, the annual increase rate is less than $0.1 \%$ in U.S. whereas it is greater than $1 \%$ in Korea. An increase in the prevalence of hypercholesterolemia, particularly high levels of LDL cholesterol, among Korean adults may be due to unfavorable changes in risk factors. The present study confirmed an increasing trend in $\mathrm{HC}$ prevalence with increasing consumption of high-fat foods over 10 years. Particularly, a noticeable secular increase in the consumption of dairy products was observed. In association analysis, consumption of dairy products and vegetable oil products was found to be positively associated with $\mathrm{HC}$ prevalence. Whole-fat milk and dairy products are food sources of saturated fat as about two-thirds of milk fatty acid is saturated. Although the findings on the effect of whole-fat dairy consumption on raising $L D L$ cholesterol are still inconsistent [25], it is quite obvious that substituting fat-free or low-fat dairy for whole-fat products is beneficial in reducing CHD risk [26]. Vegetable oil products, such as soybean oil and corn oil, are commonly used in Korea, and most of them are high in unsaturated fat and low in saturated fat. The findings of this study regarding the association between the consumption of vegetable oil products and $\mathrm{HC}$ prevalence conflict with the beneficial effects on LDL cholesterol of replacing unsaturated with saturated fat [27]. This discrepancy may be explained by the increasing consumption of heated vegetable oils in deepfried foods [28], which was reported to increase the risk of CHD [29]. According to the Dietary Reference Intakes for Koreans 2015, the recommended percentages of calories from fat range from $15 \%$ to $30 \%$ for adults aged 19 years or older [30]. This range was newly established based on the KNHANES data regarding an increasing trend in the consumption of fat \%; the previously recommended range was $15-25 \%$ [31]. In the present study, $15 \%$ of the study subjects were found to consume $20 \%$ to $25 \%$ of fat calories and contribute to an increase in the ORs of $\mathrm{HC}$ prevalence whereas only $6 \%$ of them consumed $>30 \%$ and their OR was not significant. Because these findings do not indicate causal associations, cautious interpretations are warranted and proper consumption of fat \% cannot be suggested at this time. Nevertheless, data from the national survey regarding an increasing trend in fat consumption and its association with chronic disease should not be ignored when the dietary guideline is established.

In this study, BMl was found to be steady over the study cycles, but obesity prevalence tended to be slowly increasing. Furthermore, a positive association between BMl and $\mathrm{HC}$ prevalence was found as shown in earlier data [32]. The prediction results of this study suggest that an $1 \mathrm{~kg} / \mathrm{m}^{2}$ change in BMl is associated with a $9 \%$ change in the odds of $\mathrm{HC}$ prevalence, and thus a $2 \mathrm{~kg} / \mathrm{m}^{2}$ reduction in BMl would result in a 3.3-fold reduction in HC prevalence. A meta-analysis study including 65 studies reported a $0.77 \mathrm{mg} / \mathrm{dL}$ decrease in LDL cholesterol for every $1 \mathrm{~kg}$ of weight loss [33]. According to the 2016 KNHANES report, $42 \%$ of male and $26 \%$ of female adults have a BMI of $25 \mathrm{~kg} / \mathrm{m}^{2}$ or greater and are considered high risk for $\mathrm{HC}$ [5]. For this population, implementing interventions aimed at weight control would be one of the primary prevention strategies to manage not only LDL cholesterol but also triglycerides.

In the present study, age, marital status, types of job, and income status were found to have a significant association with HC. Information on such demographic and socioeconomic factors can be utilized to identify a high-risk population. The impact of age on $\mathrm{HC}$ is expected to be greater because of an increasing size of the elderly population.

The limitations and strengths of the present study should be noted. Because of its cross-sectional design, causal associations between contributing factors and $\mathrm{HC}$ cannot be inferred from the findings of this study. Other factors which are potentially associated with $\mathrm{HC}$, such as genetic predisposition [34], shift work [35], and physical activity [36], were not evaluated; especially physical activity, which is an important modifier of cholesterol levels. In the KNHANES data, information on regular walking was available but was considered to be insufficient to reflect overall physical activity. Instead, the consumer price index for gasoline was considered in the study, because high gasoline price is possibly linked to physical activity [21]. Because LDL cholesterol levels were calculated rather than assayed directly, non-differential misclassification in the outcome might occur. However, its influence on the findings may be minimal [37]. Some strengths of the study include the availability of a large sample size through using national survey data and that a wide range of variables were considered in the analysis.

In summary, the present study analyzed pooled crosssectional data from nationwide surveys over 10 years and revealed that higher $\mathrm{BMI}$ and increasing consumption of calories from fat and some high-fat food products, such as dairy and vegetable oil products, are associated with the prevalence of $\mathrm{HC}$ defined using LDL cholesterol levels. Given the trend that $\mathrm{HC}$ prevalence, obesity, and fat consumption is gradually increasing in Korean adults, individual- and national-level efforts for weight control and proper dietary modification are needed to prevent and manage HC. At present, however, whether discouraging consumption of dairy and vegetable oil products can reduce $\mathrm{HC}$ prevalence is obscure. To clarify this issue, further studies with a prospective longitudinal design are warranted.

\section{CONFLICT OF INTEREST}

The author declares no potential conflicts of interests.

\section{ORCID}

Inkyung Baik: https://orcid.org/0000-0002-9524-4344

\section{REFERENCES}

1. Wilson PW. Established risk factors and coronary artery disease, the Framingham Study. Am J Hypertens 1994;7;7S-12S.

2. Manson JE, Tosteson H, Ridker PM, Satterfield S, Hebert P, O'Connor 
GT, Buring JE, Hennekens $\mathrm{CH}$. The primary prevention of myocardial infarction. N Engl J Med 1992;326:1406-1416.

3. Gordon DJ, Probstfield JL, Garrison RJ, Neaton JD, Castelli WP, Knoke JD, Jacobs DR Jr, Bangdiwala S, Tyroler HA. High-density lipoprotein cholesterol and cardiovascular disease. Four prospective American studies. Circulation 1989;79:8-15.

4. Lee SW, Kim HC, Lee HS, Suh I. Thirty-year trends in mortality from cardiovascular diseases in Korea. Korean Circ J 2015;45:202-209.

5. Ministry of Health and Welfare. Korea Centers for Disease Control and Prevention. Korea Health Statistics 2016: Korea National Health and Nutrition Examination Survey (KNHANES VII-1). Korea Centers for Disease Control and Prevention: Sejong, Republic of Korea, 2017.

6. Tran BT, Jeong BY, Oh JK. The prevalence trend of metabolic syndrome and its components and risk factors in Korean adults, results from the Korean National Health and Nutrition Examination Survey 2008-2013. BMC Public Health 2017;17:71.

7. Committee for the Korean Guidelines for the Management of Dyslipidemia. 2015 Korean Guidelines for the Management of Dyslipidemia: Executive Summary (English Translation). Korean Circ J 2016;46:275-306.

8. Yun S, Kim HJ, Oh K. Trends in energy intake among Korean adults, 1998-2015: Results from the Korea National Health and Nutrition Examination Survey. Nutr Res Pract 2017;11:147-154.

9. Micha R, Khatibzadeh S, Shi P, Fahimi S, Lim S, Andrews KG, Engell RE, Powles J, Ezzati M, Mozaffarian D, Global Burden of Diseases Nutrition and Chronic Diseases Expert Group NutriCoDE. Global, regional, and national consumption levels of dietary fats and oils in 1990 and 2010: a systematic analysis including 266 countryspecific nutrition surveys. BMJ 2014;348:g2272.

10. Research Committee on Serum Lipid Level Survey 1990 in Japan. Current state of and recent trends in serum lipid levels in the general Japanese population. J Atheroscler Thromb 1996;2:122-132.

11. Cohen JD, Cziraky MJ, Cai Q, Wallace A, Wasser T, Crouse JR, Jacobson TA. 30-year trends in serum lipids among United States adults: results from the National Health and Nutrition Examination Surveys II, III, and 1999-2006. Am J Cardiol 2010;106:969-975.

12. Hotchkiss JW, Davies CA, Gray L, Bromley C, Capewell S, Leyland A. Trends in cardiovascular disease biomarkers and their socioeconomic patterning among adults in the Scottish population 1995 to 2009: cross-sectional surveys. BMJ Open 2012;2.

13. Johansson I, Nilsson LM, Stegmayr B, Boman K, Hallmans G, Winkvist A. Associations among 25-year trends in diet, cholesterol and BMI from 140,000 observations in men and women in Northern Sweden. Nutr J 2012;11:40.

14. Nam GE, Han K, Park YG, Choi YS, Kim SM, Ju SY, Ko BJ, Kim YH, $\mathrm{Kim} \mathrm{EH}, \mathrm{Cho} \mathrm{KH}$, Kim DH. Trends in lipid profiles among South Korean adults: 2005, 2008 and 2010 Korea National Health and Nutrition Examination Survey. J Public Health (Oxf) 2015;37:286-294.

15. Kotseva K, De Bacquer D, Jennings C, Gyberg V, De Backer G, Rydén L, Amouyel P, Bruthans J, Cifkova R, Deckers JW, De Sutter J, Fraz Z, Graham I, Keber I, Lehto S, Moore D, Pajak A, Wood D; EUROASPIRE Investigators. Time Trends in Lifestyle, Risk Factor Control, and Use of Evidence-Based Medications in Patients With Coronary Heart Disease in Europe: Results From 3 EUROASPIRE Surveys, 1999-2013. Glob Heart 2017;12:315-322.

16. Griffey S, Piccinino L, Gallivan J, Lotenberg LD, Tuncer D. Applying national survey results for strategic planning and program improvement: the National Diabetes Education Program. Eval Program
Plann 2015;48:83-89.

17. Zhou L, Zhao $X$, Heizhati $M$, Abulikemu S, Zhang $D$, Cheng $Q$ Ouyang W, Yao X, Hong J, Wu T, Xiamili Z, Li N. Trends in Lipids and Lipoproteins Among Adults in Northwestern Xinjiang, China, From 1998 Through 2015. J Epidemiol 2018 [Epub ahead of print].

18. Kweon S, Kim Y, Jang MJ, Kim Y, Kim K, Choi S, Chun C, Khang $\mathrm{YH}$, Oh K. Data resource profile: the Korea National Health and Nutrition Examination Survey (KNHANES). Int J Epidemiol 2014;43: 69-77.

19. National Rural Living Science Institute. Food composition table, 6th ed. Suwon, Republic of Korea, 2001.

20. Friedewald WT, Levy RI, Fredrickson DS. Estimation of the concentration of low-density lipoprotein cholesterol in plasma, without use of the preparative ultracentrifuge. Clin Chem 1972;18:499-502.

21. Rashad I. Associations of cycling with urban sprawl and the gasoline price. Am J Health Promot 2009;24:27-36.

22. Baik I. Forecasting obesity prevalence in Korean adults for the years 2020 and 2030 by the analysis of contributing factors. Nutr Res Pract 2018;12:251-257.

23. Finkelstein EA, Khavjou OA, Thompson H, Trogdon JG, Pan L, Sherry B, Dietz W. Obesity and severe obesity forecasts through 2030. Am J Prev Med 2012;42:563-570.

24. Carroll MD, Fryar CD, Nguyen DT. Total and High-density Lipoprotein Cholesterol in Adults: United States, 2015-2016. NCHS Data Brief 2017;290:1-8.

25. Benatar JR, Sidhu K, Stewart RA. Effects of high and low fat dairy food on cardio-metabolic risk factors: a meta-analysis of randomized studies. PLoS One 2013;8:e76480.

26. Livingstone KM, Lovegrove JA, Givens DI. The impact of substituting SFA in dairy products with MUFA or PUFA on CVD risk: evidence from human intervention studies. Nutr Res Rev 2012;25:193-206.

27. Schwingshackl $L$, Bogensberger $B$, Benčič $A$, Knüppel $S$, Boeing $H$, Hoffmann G. Effects of oils and solid fats on blood lipids: a systematic review and network meta-analysis. J Lipid Res 2018;59: 1771-1782.

28. Narasimhamurthy K, Raina PL. Long term feeding effects of heated and fried oils on lipids and lipoproteins in rats. Mol Cell Biochem 1999;195:143-153.

29. Gadiraju TV, Patel Y, Gaziano JM, Djoussé L. Fried Food Consumption and Cardiovascular Health: A Review of Current Evidence. Nutrients 2015;7:8424-8430.

30. Ministry of Health and Welfare. The Korean Nutrition Society. Dietary Reference Intakes for Koreans 2015. Seoul, Republic of Korea, 2015.

31. The Korean Nutrition Society. Dietary Reference Intakes for Koreans 2010. Seoul, Republic of Korea, 2010.

32. Lamon-Fava S, Wilson PW, Schaefer EJ. Impact of body mass index on coronary heart disease risk factors in men and women. The Framingham Offspring Study. Arterioscler Thromb Vasc Biol 1996;16:1509-1515

33. Dattilo AM, Kris-Etherton PM. Effects of weight reduction on blood lipids and lipoproteins: a meta-analysis. Am J Clin Nutr 1992;56: 320-328.

34. Sharifi $M$, Futema $M$, Nair $D$, Humphries SE. Genetic Architecture of Familial Hypercholesterolaemia. Curr Cardiol Rep 2017;19:44.

35. Dochi M, Suwazono $Y$, Sakata K, Okubo $Y$, Oishi M, Tanaka K, Kobayashi E, Nogawa K. Shift work is a risk factor for increased total cholesterol level, a 14-year prospective cohort study in 6886 
male workers. Occup Environ Med 2009;66:592-597.

36. Bouillon K, Singh-Manoux A, Jokela M, Shipley MJ, Batty GD, Brunner EJ, Sabia S, Tabák AG, Akbaraly T, Ferrie JE, Kivimäki M. Decline in low-density lipoprotein cholesterol concentration: lipid-lowering drugs, diet, or physical activity? Evidence from the Whitehall ॥ study. Heart 2011;97:923-930.

37. Fukuyama N, Homma K, Wakana N, Kudo K, Suyama A, Ohazama H, Tsuji C, Ishiwata K, Eguchi Y, Nakazawa H, Tanaka E. Validation of the Friedewald Equation for Evaluation of Plasma LDL-Cholesterol. J Clin Biochem Nutr 2008;43:1-5. 